\title{
Anti-GnRH Vaccine PEP223
}

National Cancer Institute

\section{Source}

National Cancer Institute. Anti-GnRH Vaccine PEP223. NCI Thesaurus. Code C85464.

A peptide vaccine derived from the synthetic peptide pyroEHWSYGLRPG, corresponding to amino acids 22-31 of mouse gonadotropin releasing hormone $(\mathrm{GnRH})$, with potential immunocastration activity. PEP223 is dimerized and contains a D-lysine $(\mathrm{k})$ substitution at position 6 (pyroEHWSYkLRPG) to increase its immunogenicity. Anti-GnRH vaccine PEP223 may stimulate the immune system to mount a cytotoxic T-lymphocyte (CTL) response against $\mathrm{GnRH}$, neutralizing its activity. In turn, testosterone production and tumor cell growth may be inhibited in testosterone-sensitive tumors. 